\title{
University Accreditation Application
}

\author{
Genta Sahuri*, Habayl \\ President University \\ *Corresponding Author: genta.sahuri@president.ac.id
}

\begin{abstract}
Accreditation is very complex and delicate procedure. It has to be done carefully, mistake can lead poor accreditation result. The common mistake is human error. Handling a lot questions, the result will be less accurate. Having wrong accreditation result can give bad result to the university who may actually get good accreditation result. Accreditation application let user to modify input and assessment anytime he wants. If user includes incorrect input, he can edit it by going back to input form and if user misjudged in assessing, he can go back to assessment and fix it. So, before getting accreditation result, user simply can check the assessment point of each aspect. Thus, this feature is necessary in assisting user to complete a particular accreditation project in a more effective manner.
\end{abstract}

\section{INTRODUCTION}

Accreditation University is very complex and delicate procedure to measure University education quality. It must be done periodically and carefully. In the process, user prohibited to make any mistake, so the process must be done carefully. In most case, mistakes happen from user (Human error).

With tons of work that user handle, human error frequently happens. It is hard to notice unless user recheck it again. It is delicate work, more attention require from user.

If mistakes in assessment do not get detected, it can damage the university who is being assessed. The university may get bad result while they suppose get good result. It occurs not often since users always check it again before they release the result.

\section{Problem Statement}

This research intends to implement application using Graphic User Interface (GUI) to solve issues in Accreditation University. With the rapid grow of university in Indonesia, accreditation is necessary to ensure the quality of university. It also means increasing workload to accredit university. This research will make accreditation assessment efficient by creating application to help automatically calculate university accreditation and give more accurate accreditation result.

\section{Goal}

This research attempts to solve the most common problems that are faced by assessor of accreditation, such as human error or inefficient . Furthermore, this research intend to create application that automatically calculates accreditation result and provide user with easiness in accreditation process. The application comes with edit feature, so if user did mistake, he can just go back again then fix it.

Users will be provided with features such as data management, which user can store filling data, edit the data and even attach document. Moreover, features to automatically calculates input and generate accreditation are also available. Besides, there are also features that could help users to restart their accreditation process called reset function.

In conclusion, the objective of this research is to build an accreditation application. The application includes data management, calculation and reset features.

\section{LITERATURE STUDY}

University accreditation is a reflection of the performance, the quality, efficiency, and relevance of study program that is conducted by university. Accreditation is not given to the university, but to each major in the university. Thus, it is possible that a university have majors with different accreditation.

Accreditation is done regularly to keep the quality of university. There are many things that need to be assessed which are the infrastructure, facility, human resource, university management, etc. "University accreditation is a reflection of the performance, the quality, efficiency, and relevance of study program that is conducted by university." [1].

\section{SYSTEM ANALYSIS}

\section{Model View Controller (MVC)}

Model view controller (MVC) is a method to create applications by separating data (model) from the outlook (view) and how to process it (controller). Nowadays, in its implementation, most 
of application framework is based on MVC architecture.

MVC separates the development of applications based on the key components to build an application such as data manipulation, user interface, and part of the control in a application. In other words, MVC is an approach, which used in framework in order to have an easier way in developing application. Using MVC, architecture will be completely clean, so that programmers can separate between views (view), database (model), and controllers (controllers) which control the view and the model. Figure 5 shows the diagram of MVC Architecture.

Here are the MVC components:

- Model represents the data structure. Model typically contains functions that assist a person in managing the resource database as input to the database, update the data and others. Model also used to fetch data from database, and then the data will be shown in view.

- View is a component of MVC(Model View Controller) concept which shows the interface of the developed application. View displays dynamic data of the application. A view typically is a form page of an application, nevertheless, in MVC Visual studio, a view can also be a page fragment. In the development, it uses form load and mouse move functions as view module.

- The development of this application includes several controllers that are used as the hub for transition of data from the application interface (view) to the model. Each controller contains some logical functions responsible to process the data from the user, before sending them for further inspection by the model.

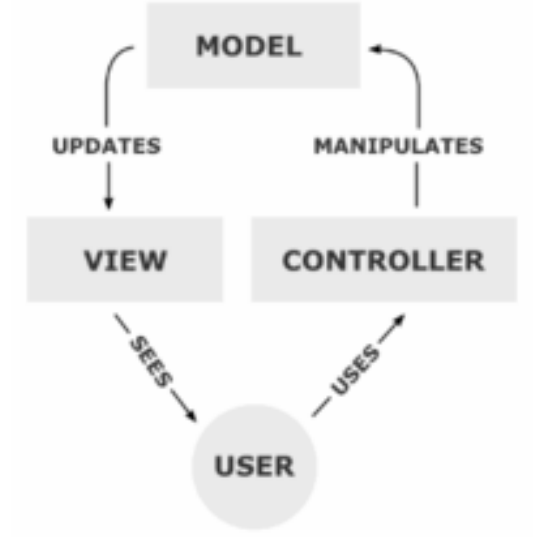

Figure 5 MVC Architecture

\section{Use Case Diagram}

System architecture is a formal view of more description and representation of the system. In here, more views of the system will be shown, starting from the structure until the behavior. In addition, there will be use case diagram, use case narrative, and activity diagram shown in this section. "A Use Case is a series of related interactions between a user (more generally an "actor") and a system that enables the users to achieve a goal" [2]. Use Case Diagram is a view of the system boundaries that identifies the use case, which defined to support the solution.

Furthermore, use case is a narrative conversation between actors/users and features that come as the solution. Use case is made to define the core elements and processes of the system and it explains about the whole system from user point of view. The key elements are termed as actors and the processes are termed as use cases. The Use Case diagram shows which actors interact with each use case, Figure 6 shows Use Case Diagrams.

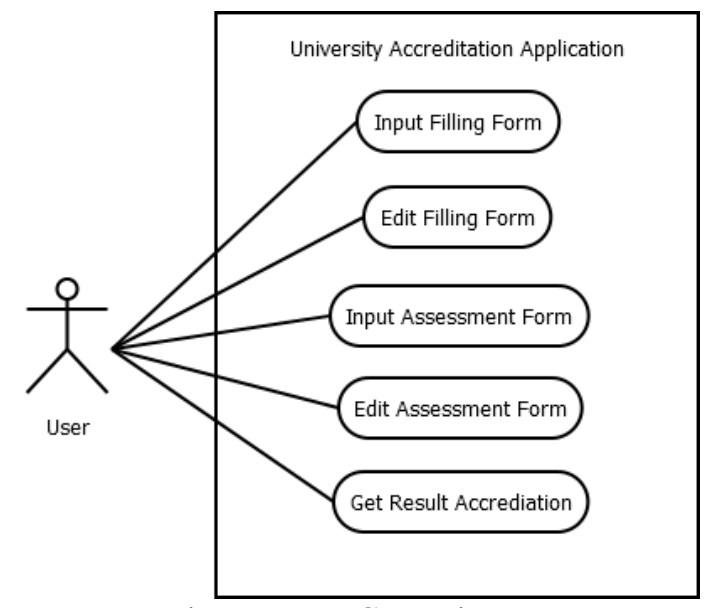

Figure 6 Use Case Diagram

\section{User Interface Design}

University Accreditation Application is an interactive Graphic User Interface (GUI) application aims to make simple and comfortable accreditation assessment. For that reason, the design is the most important things beside the features because the interface needs to be fresh, catchy, and remarkable.

\subsection{User Interface Design Concept}

Figure 7(a) is Main Form Design. The design consists of main menu strip, application logo, foot note and reset button. Main menu strip is used as portal for user to go into designed section. This section consists of borang, self evaluation, 
assessment, and accreditation section. Application logo where used to display the logo. Footnote is used to display typical note about the application. Reset button is used to reset database value to default.

Figure 7(b) is Study Program Form Design. The design consists of header, body, and footer. The header consists of text written "Identity of Study Program". The main body is designed to put study program information. To save data of study program identity and to go to the next page there are 2 buttons in the footer that can be used.

Figure 7(c) is Input Form Design. The design consists of header, body, and footer. Written text "Standard Accreditation" in the header. The main body consists of text written "Question number" and "Explanation" and text boxes for answering. There are 3 buttons in the footer; to save data of accreditation survey, to go to the previous page and to go to the next page.

\section{Entity Relationship Diagram}

Entity Relationship Diagram in this system are three entities implemented as a table in the database of the application. The main entities in this Accreditation University are the Study program, University, and Faculty, these entities designed to collect and connect data from the other entities.

ERD of accreditation application is a complex and large subject, it is created by three major part, Accreditation University, Result A and Result B. Accreditation University is the group of entities that hold important data for university identity and accreditation rank. While Result A and Result B are groups of entities that support the accreditation process.

Accreditation University ERD functions as information pool, it is separate from entities of process. The data contained is not necessary for assessment process but essential for describing which university currently being assessed.

Result ERD is useful as data information to assessment process. The data temporary stored until the process is finished.

\section{Modules Development}

In Visual Studio, the divisions of the main modules are divided into three parts, which are Model, View, and Controller. All of the majority change or improvement will be focused on the subject of those three main modules. However, several additional modules will be incorporated to the main modules in order to improve the application.

\subsection{Model Module}

Model interacts closely with database. Model contains functions used to retrieve, store, and update information within the database. Model executes functions which are closely related to some functions executed by the controller, therefore making the interaction between the three modules possible.

\subsection{Controller Module}

The development of this application includes several controllers that are used as the hub for transition of data from the application interface (view) to the model. Each controller contains some logical functions responsible to process the data from the user, before sending them for further inspection by the model.

\subsection{View Module}

View concept which shows the interface of the developed application. View displays dynamic data of the application..

\section{USER INTERFACE DEVELOPMENT}

The development of this application involves the creation of dynamic user interface which is displayed through the view of the system. The user interface design is created based on the use case and activity diagrams developed earlier.

Figure 10(a) shows the Main page of the application. Main page interface has Toolstrip Main Menu (Menu utama) on left above, banner in middle which is written "Aplikasi Akreaditasi", below there is a warning note about Total Reset Button below it. Toolstrip Main menu is used as portal, user can go directly to any section.

Figure 10(b) shows Study Program Form. It is where user put Study Program information. It consists of several textbox which represent the identity of the Study Program and two buttons which function to save the data in textbox and to continue to next form.

Figure 10(c) shows Input Form Design. Input Form Design is the place where user put all field report of accreditation. These forms consist of several labels and textbox. Label is where the question or instruction been putted. Textbox is where the answer or respond from the instruction been putted 


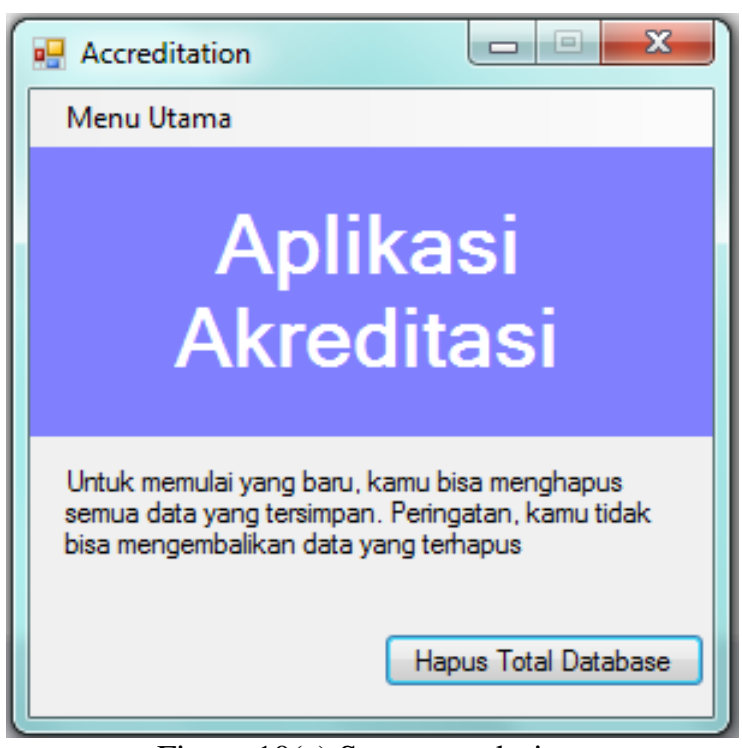

Figure 10(a) Start page design

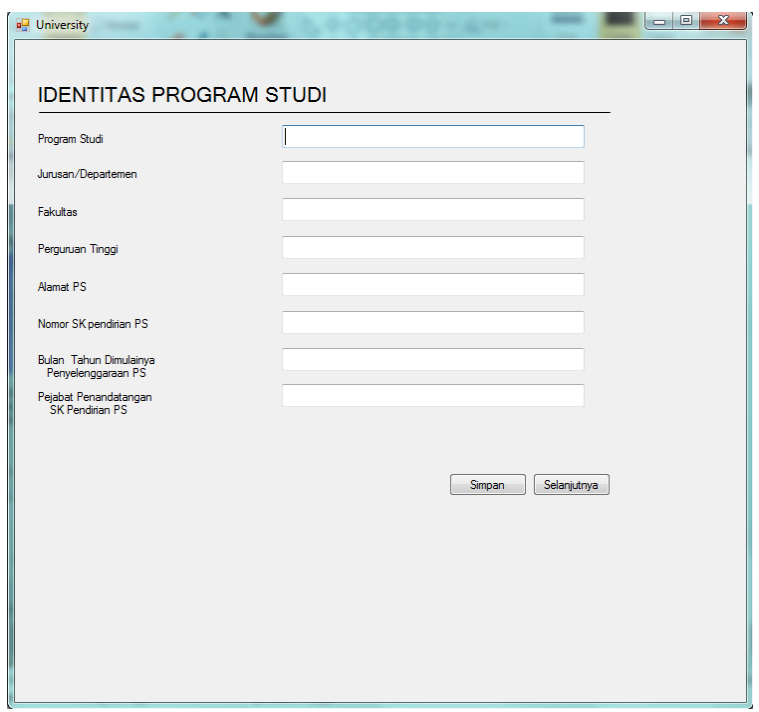

Figure 10(b) Study program design

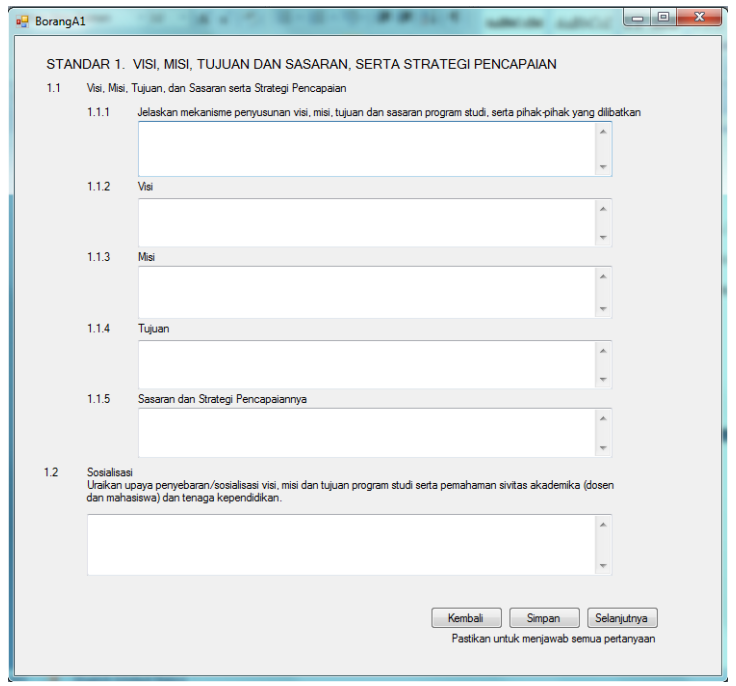

Figure 10(b) Study program design

\section{System Testing}

The application needs to be tested to ensure that every designed function of the application can be run properly. To run a more comprehensive and detailed testing, the testing will be done based on several scenarios.

\subsection{Scope and Limitation}

The system testing is conducted based on the system requirements. Therefore, the tests need to refer to system's functional requirements and resource requirements. In order to accomplish the expected result, the system testing requires Microsoft Visual Studio 2010 and MySQL Workbench 5.2 with MySQL.Net Connector for Connection Bridge. The information provided in system testing is based on author's assumption and some accreditation sample.

\subsection{Testing Scenarios}

The testing scenario aims to demonstrate that the application meets its requirements. There are several policies inside the testing scenario such as all functions accessed through menus will be tested, all functions will be tested with correct and incorrect input. Then successful tests will show that the application operates as intended and displays the expected outputs.

The testing scenario distributed into two types, the positive and the negative scenario. The positive scenario provides the correct input while the negative scenario provides the incorrect input.

\section{CONCLUSIONS}

Conclusion will be declaring during system development. There are several conclusions can be drawn from University Accreditation Application:

- University Accreditation Application has complex database system. There are a lot of table data created to accommodate accreditation requirement and some of them related to each other, which create huge entity relationship diagram. Because of it, huge attention in research development is given to database system.

- Accreditation University can be used for Badan Akreditasi Nasional- Perguruan Tinggi(BANPT). Because it already fulfills the Accreditation Standards from BAN-PT.

\section{REFERENCES}

[1] Badan Akreditasi Nasional.Preface [Online] August 2008 -http://ban- 
IT FOR SOCIETY, Vol. 03, No. 02

ISSN 2503-2224

pt.kemdiknas.go.id/index.php?option=com_con tent $\&$ view $=$ article $\&$ id $=19 \&$ Itemid=27\&lang=e $\mathrm{n} /$.

[2] Accompa. [Online] September 2009 http://www.accompa.com/productmanagement-blog/2009/09/19/use-casesdefinition-requirements-management-basics/.

[3] Model View Controll. [Online] http://en.wikipedia.org/wiki/Model\%E2\%80\%9 3 view\%E2\%80\%93controller. 